\title{
High expression of Rab31 confers a poor prognosis and enhances cell proliferation and invasion in oral squamous cell carcinoma
}

\author{
XIAOGUANG LI* ${ }^{*}$ FENGSHUO ZHU*, ZHONGLONG LIU, XIAO TANG, \\ YU HAN, JUNJIAN JIANG, CHUNYUE MA and YUE HE
}

\begin{abstract}
Department of Oral Maxillofacial-Head and Neck Oncology, Shanghai Ninth People's Hospital, College of Stomatology, Shanghai Jiao Tong University School of Medicine; National Clinical Research Center for Oral Disease; Shanghai Key Laboratory of Stomatology and Shanghai Research Institute of Stomatology, Shanghai 200011, P.R. China
\end{abstract}

Received August 10, 2020; Accepted December 14, 2020

DOI: $10.3892 /$ or.2021.7940

\begin{abstract}
Dysregulation of Rab proteins has been observed in various types of cancer. Ectopic expression of Rab31, a member of the Rab protein family, is involved in cancer development and progression. However, the specific role and potential molecular mechanism underlying the functions of Rab31 remain largely unknown. Therefore, the current study aimed to investigate the functions of Rab31 in the development of cancer. Human oral squamous cell carcinoma (OSCC) samples were examined to determine the expression profile of Rab31 and its association with the clinicopathological characteristics of patients with OSCC. Knockdown of Rab31 expression with short hairpin RNA was performed to analyze the functions of Rab31 in vitro and in vivo. The expression of Rab31 was significantly elevated in human OSCC samples compared with that in normal oral mucosal epithelial tissues, and high expression levels were associated with high pathological grades. Furthermore, positive expression of Rab31 was associated with a poor prognosis in patients with OSCC. In addition, knockdown of Rab31 expression suppressed OSCC cell proliferation and induced apoptosis compared with those in the control-transfected cells, which may have been caused by downregulated cyclin D1 and survivin expression and upregulated B-cell lymphoma 2 expression. The invasive ability of OSCC cells
\end{abstract}

Correspondence to: Dr Yue He or Dr Chunyue Ma, Department of Oral Maxillofacial-Head and Neck Oncology, Shanghai Ninth People's Hospital, College of Stomatology, Shanghai Jiao Tong University School of Medicine; National Clinical Research Center for Oral Disease; Shanghai Key Laboratory of Stomatology and Shanghai Research Institute of Stomatology, 639 Zhi Zao Ju Road, Shanghai 200011, P.R. China

E-mail: xiaoguang927@163.com

E-mail: mscofield39353@live.cn

*Contributed equally

Key words: Rab31, oral squamous cell carcinoma, prognosis, proliferation, invasion was also abrogated by Rab31 silencing compared with that in the control-transfected cells, which was associated with downregulated $\mathrm{N}$-cadherin and matrix metalloproteinase-9 expression levels and upregulated levels of E-cadherin expression. Furthermore, silencing Rab31 in OSCC cell lines, when compared with the control-transfected cells, significantly reduced tumor growth and inhibited the expression of survivin, Ki-67 and N-cadherin in vivo. By contrast, the expression levels of E-cadherin were increased. Taken together, the results of the present study supported important roles for Rab31 in regulating OSCC cell proliferation, apoptosis and invasion and may facilitate the identification of a new therapeutic target for the treatment of OSCC.

\section{Introduction}

Oral squamous cell carcinoma (OSCC) is the most common malignant neoplasm of the oral cavity (1). Despite recent advances in screening and treatment, the current 5-year survival rate of OSCC is $\sim 50 \%$, which is generally attributed to either distant metastasis or locoregional recurrence (2-4). Molecular targeted inhibitors, such as cetuximab, were previously considered to be potentially effective measures; however, the long-term clinical results have been mixed or unfavorable, with a large number of patients ultimately exhibiting resistance (5). Therefore, revealing the molecular mechanisms underlying the carcinogenesis of OSCC, which may provide a basis for other therapeutic targets, is necessary.

Aberrant expression of Ras-related proteins has been frequently reported in various types of human cancer (6). Dysregulation of Ras-related proteins often leads to a loss of control of cell proliferation, adhesion and migration, which affects disease progression and prognosis $(6,7)$. The Ras-related protein Rab31, also termed Rab22B, is a member of the Rab family $(8,9)$ involved in the organization of the trans-Golgi network and transport carrier formation (10). Previous studies have reported that high Rab31 expression levels are associated with cancer. For example, expression profiling analyses have identified Rab31 as one of 11 genes robustly upregulated in estrogen receptor-positive compared with estrogen receptor-negative breast cancer (11). Additionally, Rab31 has 
been reported to promote the proliferation of cancer and normal cells $(12,13)$.

The potential effects of the Rab family on head and neck cancer (HNC) have been identified in a number of studies with contradictory results. Rab25, a member of the Rab11 subfamily, was reported to regulate cellular invasion and metastasis in HNC (14). Similar inhibitory effects of Rab25 were confirmed in another study, which demonstrated decreased expression in advanced metastatic oral and oropharyngeal cancer (15). By contrast, Rab5a, Rab9 and Rab14 were observed in several studies to exert cancer-promoting functions, thus serving as oncogenes rather than tumor suppressors (16-18). Rab5a can upregulate the expression of various cell cycle-associated proteins and regulate the activity of a number of signaling pathways, such as the ERK/MMP signaling pathway (16). The vast discrepancies among Rab family proteins indicate the complex mechanisms linking $\mathrm{Rab}$ and HNC. Despite being a core member of the Rab family, the potential functions of Rab31 in OSCC remain unknown. Therefore, the present study aimed to investigate the expression of Rab31 in human OSCC tissues and analyze the associations between Rab31 expression levels and the clinicopathological characteristics of patients with OSCC, as well as determine the functional roles of Rab31 in OSCC by in vitro and in vivo experiments.

\section{Materials and methods}

Ethics statement. All experiments in the present study were approved by the Independent Ethics Committee and Animal Experimental Ethical Inspection of the Shanghai Ninth People's Hospital, Shanghai Jiao Tong University School of Medicine and performed at the Shanghai Ninth People's Hospital. The approval numbers were SH9H-2019-T117-1 for human tissues and HKDL-2017-304 for animal studies. All experiments were performed in 2019.

OSCC samples. A total of 54 human OSCC and 16 normal oral mucosa samples were obtained from patients with OSCC and healthy individuals, respectively, at the Shanghai Ninth People's Hospital between January 2014 and December 2017. Each patient provided informed written consent for enrollment in the current study. The median follow-up duration was 31 months with no patients lost to the follow-up. The most affected sites among the OSCC samples were the tongue $(n=31,57.4 \%)$, followed by the floor of mouth $(n=14,25.9 \%)$, bucca $(n=6,11.1 \%)$ and upper gingiva $(n=3,5.6 \%)$. Healthy tissue was taken from the tongue $(n=7,43.8 \%)$, bucca $(n=5,31.2 \%)$, or lower gingiva $(n=4,25.0 \%)$. Histological diagnosis, pathological grading and Tumor-Node-Metastasis (TNM) staging of the samples were performed by three independent pathologists based on the 8th edition of the American Joint Committee on Cancer (AJCC) staging system (19).

Antibodies. The primary antibodies used in the current study were as follows: Rabbit anti-Rab31 [1:200 for immunohistochemistry (IHC) and immunofluorescence (IF); cat. no. ab230881; Abcam], rabbit anti-Ki-67 (1:200 for IHC; cat. no. ab15580; Abcam), rabbit anti-Survivin [1:200 for IHC, 1:1,000 for western blotting (WB); cat. no. 2808], rabbit anti-cyclin D1 (1:1,000 for WB; cat. no. 2978), rabbit anti-B-cell lymphoma 2 (Bcl2; 1:1,000 for WB; cat. no. 2978), rabbit anti-E-cadherin (1:200 for IHC, 1:1,000 for WB; cat. no. 3195) and rabbit anti-N-cadherin (1:200 for IHC, 1:1,000 for WB; cat. no. 3116) (all from Cell Signaling Technology, Inc.).

IHC and IF staining. The OSCC samples were fixed $10 \%$ neutral buffered formalin at room temperature for $12 \mathrm{~h}$. Fixed paraffin-embedded tissues were cut into 4- $\mu \mathrm{m}$ sections. For IHC staining, antigen retrieval was performed with citrate buffer (pH 6.0) under $121^{\circ} \mathrm{C}$ for $90 \mathrm{sec}$. Following incubation with $0.3 \%$ hydrogen peroxide and $5 \%$ normal goat serum (cat. no. 5425; Cell Signaling Technology. Inc.) for $30 \mathrm{~min}$ at $4^{\circ} \mathrm{C}$, the sections were incubated with primary antibodies at $4^{\circ} \mathrm{C}$ overnight. The following day, the sections were incubated with biotinylated goat anti-rabbit or anti-mouse serum IgG antibodies (Cell Signaling Technology, Inc, \#7074 and \#7076), followed by incubation with horseradish peroxidase (HRP)-conjugated streptavidin-biotin for $30 \mathrm{~min}$ at room temperature. A 3,3'-Diaminobenzidine Staining kit (Fuzhou Maixin Biotech Co., Ltd.) was used at room temperature for 5 min for section staining, followed by counterstaining with hematoxylin $90 \mathrm{sec}$. For IF, the incubation with primary antibodies was as aforementioned; subsequently, the sections were incubated at room temperature for $1 \mathrm{~h}$ with a secondary Alexa Fluro 594 anti-rabbit antibody (cat. no. A-11037; 1:1,000; Invitrogen; Thermo Fisher Scientific, Inc.,) and stained with 4',6'-diamidino-2-phenylindole (DAPI; Jackson ImmunoResearch Laboratories, Inc.) Following 1-h incubation, images were captured using a fluorescence microscope (Olympus Corporation) at x100 magnification in 10 random fields with $\geq 500$ cells, and the number of cells with different staining intensities was counted by two pathologists. When no observable staining was present, the membrane or nuclear staining was incomplete or faint in $\leq 10 \%$ of cancer cells, the sample was defined as Rab31-negative.

Cell culture. The human OSCC cell lines SCC-4, SCC-9, SCC-25 and CAL27 were maintained in Dulbecco's modified Eagle's medium (DMEM)/F12 (HyClone; Cytiva) with $10 \%$ fetal bovine serum (FBS; HyClone; Cytiva). Cells were cultured at $37^{\circ} \mathrm{C}$ in a humidified atmosphere with $5 \% \mathrm{CO}_{2}$. Primary human oral epithelial cells (HOECs) were cultured as follows: Fresh oral mucosa tissues were obtained from healthy adults undergoing third molar extraction. Written consent was obtained from these healthy adults for this study. The obtained tissues were washed with PBS without calcium or magnesium three times, cut into $0.3-\mathrm{cm}^{2}$ pieces, incubated with $2 \mu \mathrm{g} / \mathrm{ml}$ Dispase solution (MilliporeSigma) for $18 \mathrm{~h}$ at $4^{\circ} \mathrm{C}$ and trypsinized with $0.125 \%$ trypsin and $0.01 \mathrm{mM}$ EDTA. The cell suspension was centrifuged at room temperature at $300 \mathrm{xg}$ for $10 \mathrm{~min}$, and the cells were cultured with keratinocyte serum-free medium (Invitrogen; Thermo Fisher Scientific, Inc.) with $25 \mu \mathrm{g} / \mathrm{ml}$ bovine pituitary extract (Cell Applications, Inc.) and $0.2 \mu \mathrm{g} / \mathrm{ml}$ EGF recombinant protein (Invitrogen; Thermo Fisher Scientific, Inc.).

Establishment of Rab31-knockdown OSCC cell lines. Short hairpin (sh)RNA sequences (shRNA1 and shRNA2) 
specific for Rab31 and a negative control shRNA were designed and synthesized by Shanghai GenePharma Co., Ltd. The sequences were as follows: shRNA1, 5'-CCGGTT ATGTGTATGGGATTCTAAACTCGAGTTTAGAATCCC ATACACATAATTTTTG-3'; shRNA2, 5'-GTACCGGAG TGCGACCTCTCAGATATTACTCGAGTAATATCTGAG AGGTCGCACTTTTTTTG-3'; and control shRNA, 5'-TTC TCCGAACGTGTCACGT-3'. For the construction of human Rab31-specific shRNA plasmids, the two shRNA sequences were separately inserted at the $B a m \mathrm{HI} / E c o \mathrm{RI}$ restriction sites of a pGLVU6/Puro lentiviral vector (Shanghai GenePharma Co., Ltd). The lentiviral expression vectors and packaging plasmids were co-transduced into $293 \mathrm{~T}$ cells (American Type Culture Collection), a highly transfectable derivative of human embryonic kidney 293 cells, according to the lentiviral vector manufacturer's instructions. Briefly, $1.6 \times 10^{4}$ cells were added to fresh medium in a 96-well plate; $5 \mathrm{ml}\left(1 \times 10^{8} \mathrm{TU} / \mathrm{ml}\right)$ of lentiviral particles were added, and the plates were incubated for $18 \mathrm{~h}$ at $37^{\circ} \mathrm{C}$ in a humidified incubator with $5-7 \% \mathrm{CO}_{2}$. The $293 \mathrm{~T}$ cells were transfected with the pGLVU6 vector with the packaging plasmids pGag/Pol, pRev, and pVSV-G using RNAi-Mate (Shanghai GenePharma Co., Ltd.). The viral particles were harvested at $48 \mathrm{~h}$ post-transfection. Subsequently, $5 \mathrm{ml}\left(1 \times 10^{8} \mathrm{TU} / \mathrm{ml}\right)$ of lentiviral particles per $1.6 \times 10^{4}$ cells) were incubated with SCC-4 or SCC-25 cells for $10 \mathrm{~h}$ at $37^{\circ} \mathrm{C}$ in a humidified incubator with $5-7 \% \mathrm{CO}_{2}$ in the presence of $6 \mu \mathrm{g} / \mathrm{ml}$ polybrene (MilliporeSigma) (20). Rab31-knockdown cells were selected with $2 \mu \mathrm{g} / \mathrm{ml}$ puromycin at $37^{\circ} \mathrm{C}$ in a humidified incubator ( $R \& D$ Systems, Inc.); the medium was replaced with fresh puromycin-containing medium every 3-4 days until resistant colonies were identified.

Colony formation assays. SCC-4 and SCC-25 cells transduced with the negative control or Rab31-specific shRNA were seeded in 6-well plates at a density of 2,000 cells/well at $37^{\circ} \mathrm{C}$ in a humidified incubator with $5-7 \% \mathrm{CO}_{2}$. One week later, the cell colonies were fixed with $4 \%$ formaldehyde for $15 \mathrm{~min}$ at room temperature and stained with $0.05 \%$ crystal violet at room temperature for 20 min (Sigma-Aldrich; Merck KGaA). The numbers of colonies were then counted and recorded under a bright-field microscope (EVOS FL Auto Imaging System, v1.6 software; Thermo Fisher Scientific, Inc.).

Cell proliferation assay. A Cell Counting Kit-8 (CCK-8; Dojindo Molecular Technologies, Inc.) assay was used to assess the proliferative ability of OSCC cells. Briefly, 300 SCC-4 or SCC-25 cells per well transduced with the negative control or Rab31-specific shRNA were seeded in a 96-well plate. After 5 days, the cells were incubated with a CCK-8 solution for $4 \mathrm{~h}$ at $37^{\circ} \mathrm{C}$ in a humidified incubator with $5-7 \% \mathrm{CO}_{2}$. The plates were analyzed with a plate reader at a wavelength of $450 \mathrm{~nm}$.

Flow cytometry. The SCC- 4 and SCC- 25 cells ( $1 \times 10^{6}$ cells/well) transfected with or without shRNA targeting Rab31 were used for flow cytometry analyses. The cells were induced with Camptothecin stock solution (cat. no. C-9911; Sigma-Aldrich; Merck KGaA). The cells were incubated for $4-6 \mathrm{~h}$ at $37^{\circ} \mathrm{C}$, and Annexin V/propidium iodide (PI) (BD Pharmingen,
Cat. no. 556570; BD Biosciences) staining was performed according to the manufacturer's instructions. The cells were washed twice and resuspended in $1 \mathrm{X}$ binding buffer at $1 \times 10^{6}$ cells $/ \mathrm{ml}$. Subsequently, $5 \mu \mathrm{l}$ Annexin V and 5 PI were added and incubated for $15 \mathrm{~min}$ at $25^{\circ} \mathrm{C}$ in the dark. The late apoptotic cells were counted with a BD FACSCalibur flow cytometer (BD Biosciences) using FlowJo version 7.6 software (BD Biosciences).

Enzyme-linked immunosorbent assay. The protein level of MMP9 in the supernatants of SCC-4 and SCC-25 cell cultures (transfected with the negative control or Rab31-specific shRNA) was quantified using the Human MMP-9 Quantikine ELISA kit (cat. no. DMP900; R\&D Systems, Inc.) according to the manufacturer's instructions. Briefly, SCC-4 and SCC-25 cells transfected with or without shRNA targeting Rab31 were cultured in DMEM containing 10\% FBS. The cells were washed with PBS three times and cultured with serum-free DMEM for $24 \mathrm{~h}$ at $37^{\circ} \mathrm{C}$. The supernatants were harvested for analysis by centrifugation at $300 \mathrm{x} \mathrm{g}$ for $10 \mathrm{~min}$ at $4^{\circ} \mathrm{C}$. The optical density was measured at $450 \mathrm{~nm}$, and the protein concentration was determined by comparing the relative absorbance of the samples with a standard curve.

Cell invasion assay. Costar Transwell inserts ( $8-\mu \mathrm{m}$ pore size; Corning, Inc.) coated with a matrix gel (BD Pharmingen; $\mathrm{BD}$ Biosciences) at $37^{\circ} \mathrm{C}$ for $30 \mathrm{~min}$ were used for the cell invasion assay. SCC-4 and SCC-25 cells transduced with negative control or Rab31-specific shRNA were seeded in the upper chamber at a density of $2 \times 10^{4}$ cells/well in FBS-free DMEM/F12; medium and 10\% FBS were added to the lower chamber. Following incubation at $37^{\circ} \mathrm{C}$ for $24 \mathrm{~h}$, the cells in the upper chamber were removed with a cotton swab. The cells in the lower chamber were fixed with $5 \%$ glutaric dialdehyde for $15 \mathrm{~min}$ at room temperature and stained with $0.1 \%$ crystal violet for $20 \mathrm{~min}$. The invasive cells were imaged and counted under an Olympus IX73 inverted microscope at x400 magnification in five fields per sample using ImageJ 1.48 software (National Institutes of Health).

In vivo experiments. Female athymic BALB/c nude mice (weight, 18-20 g; age, 5-6 weeks) used in the current study were purchased from Hunan Silaike Jingda Laboratory Animal Co., Ltd. The experiments were performed according to the institutional guidelines of The Public Experimental Platform Center of Zhejiang. Nude mice were housed in sterile laminar flow cabinets under specific pathogen-free conditions (humidity, $50 \%$; temperature, $25^{\circ} \mathrm{C}$;

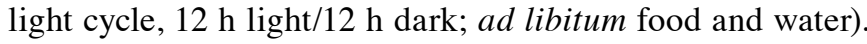
SCC-25 cells $\left(1 \times 10^{6}\right)$ were suspended $1 \mathrm{ml}$ DMEM for the injection. The SCC-25 cells transduced with control $(n=5)$ or Rab31-specific $(n=5)$ shRNA were inoculated into the right flank of nude mice. Tumor volumes was measured with a caliper every other day and calculated according to the following formula: Volume $=\left(\right.$ width $^{2} \mathrm{x}$ length $) / 2$. On day 28 , the mice were sacrificed using $\mathrm{CO}_{2}$ inhalation by adjusting the air displacement rate at $10-30 \% / \mathrm{min}$. Exposure to $\mathrm{CO}_{2}$ was continued for at least $5 \mathrm{~min}$ after respiratory arrest. Euthanasia was confirmed by cervical dislocation, and the tumors were collected. 
$R N A$ extraction and reverse transcription-quantitative $(R T-q)$ $P C R$. Total RNA was extracted from human OSCC or normal oral epithelial cells and mouse tumors using TRIzol ${ }^{\circledR}$ reagent (Thermo Fisher Scientific, Inc.) according to the manufacturer's instructions. First-strand cDNA was synthesized using $1 \mu \mathrm{g}$ total RNA and a RevertAid First Strand cDNA Synthesis kit (Fermentas; Thermo Fisher Scientific, Inc.). qPCR was performed on a ViiA 7 Real-Time PCR system (Thermo Fisher Scientific, Inc.) with the following thermocycling conditions: $2 \mathrm{~min}$ at $95^{\circ} \mathrm{C}$, followed by 40 cycles of $10 \mathrm{sec}$ at $95^{\circ} \mathrm{C}, 30 \mathrm{sec}$ at $60^{\circ} \mathrm{C}$ and $30 \mathrm{sec}$ at $72^{\circ} \mathrm{C}$. All experiments were performed in triplicate. The relative RNA expression levels were calculated using the $2^{-\Delta \Delta \mathrm{Cq}}$ method (21). $\beta$-actin was used as the internal control. The primer sequences are listed in Table I.

Protein extraction and WB. Total protein was extracted from cells or mouse tumors using cell lysis buffer (Pierce; Thermo Fisher Scientific, Inc.). Protein quantification was conducted using a Bradford assay; $20 \mu \mathrm{g}$ of protein was loaded per lane, separated by SDS-PAGE (10\%) and transferred to polyvinylidene difluoride membranes (Merck KGaA). The membranes were incubated with primary antibodies overnight at $4^{\circ} \mathrm{C}$. The following day, the membranes were washed with $1 \mathrm{X}$ PBS $+0.1 \%$ Tween-20 and incubated with an HRP-conjugated anti-rabbit IgG secondary antibody (1:3,000; cat. no. 7074S; Cell Signaling Technology, Inc.) for $60 \mathrm{~min}$ at room temperature. An enhanced chemiluminescence kit (Thermo Fisher Scientific, Inc.) was used for protein visualization. $\beta$-actin (1:2,000; cat. no. 84575; Cell Signaling Technology, Inc.) was used as the loading control.

Statistical analysis. Data are presented as the mean \pm SEM. GraphPad Prism 5.0 software (GraphPad Software, Inc.) was used to analyze data. Student's t test or one-way ANOVA with Tukey's post hoc test was used for statistical comparisons. The associations between Rab31 expression levels in normal and cancerous tissues, and those with different pathological characteristics were analyzed by Fisher's exact test. Kaplan-Meier survival analysis and log-rank test were performed using SPSS 20.0 (IBM Corp.). $\mathrm{P}<0.05$ was considered to indicate a statistically significant difference.

\section{Results}

Rab31 is expressed at high levels in human OSCC tissues. To investigate the expression of Rab31 in OSCC tissues, 54 human OSCC and 16 normal oral mucosa tissue specimens were used in the current study. Representative images of Rab31 IHC staining (normal mucosa, Rab31-negative OSCC and Rab31-positive OSCC) are presented in Fig. 1A. The results of IF demonstrated that Rab31 was mainly located in the membrane and cytoplasm of cancerous epithelial cells (Fig. 1B). Among the OSCC samples, 55.55\% (30/54) were positive for Rab31, and the expression levels of Rab31 were significantly higher in human OSCC tissues compared with the normal oral mucosa samples $(\mathrm{P}=0.002$; Table II $)$.

Rab31 expression is associated with a high pathological grade and poor prognosis in human OSCC. To determine the relationship between Rab31 and the clinicopathological
Table I. Primer sequences used in the present study.

\begin{tabular}{ll}
\hline Gene & \multicolumn{1}{c}{ Sequence $\left(5^{\prime} \rightarrow 3^{\prime}\right)$} \\
\hline Rab31 & F: TGTCTTCTCGGGGACACGGGA \\
& R: CACGATGTTCTCTGGGCCATGCTC \\
Cyclin D1 & F: CCGCCTCACACGCTTCCTCTC \\
& R: TCCTCCTCGGCGGCCTTGGGG \\
E-cadherin & F: CCCATCAGCTGCCCAGAAAATGAA \\
& R: CTGTCACCTTCAGCCATCCTGTT \\
N-cadherin & F: CGAGCCGCCTGCGCTGCCAC \\
& R: CGCTGCTCTCCGCTCCCCGC \\
Bcl-2 & F: TTCTTTGAGTTCGGTGGGGTC \\
& R: TGCATATTTGTTGGGGCAGG \\
Survivin & F: TGCCTGGCAGCCCTTTCTCA \\
& R: TGGCACGGCGCACITTCTTC \\
F-actin & F: ATCACCATTGGCAATGAGCG \\
& R: ATCACCATTGGCAATGAGCG
\end{tabular}

Table II. Rab31 expression levels in human OSCC and healthy mucosa samples.

\begin{tabular}{lcccc}
\hline & & \multicolumn{2}{c}{ Rab31 } & \\
\cline { 3 - 4 } Tissue samples & Total & Negative & Positive & P-value \\
\hline Mucosa & 16 & 14 & 2 & \\
OSCC & 54 & 24 & 30 & 0.002 \\
\hline
\end{tabular}

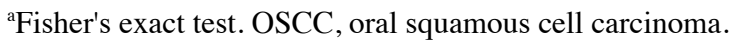

characteristics of patients with OSCC, the associations between Rab31 expression levels and patient TNM stage, pathological grade and prognosis were analyzed. Due to the limited number of cases with poor differentiation $(n=4)$, pathological grades were compared between grades I and II/III. In addition, since no T4 stage cases were included in the present study, T1 and T2 were considered early-stage OSCC. and T3 was considered late-stage OSCC for the comparison. The results demonstrated that positive expression of Rab31 was associated with a high pathological grade $(\mathrm{P}=0.016)$, whereas no significant associations were observed between Rab31 expression levels and tumor size $(\mathrm{P}=0.363)$ or lymph node involvement ( $\mathrm{P}=0.799)$ (Table III). Notably, Kaplan-Meier analysis with the log-rank test revealed that patients with positive expression of Rab31 presented with shorter survival times compared with patients who were negative for Rab31 expression ( $\mathrm{P}=0.004$; Fig. $1 \mathrm{C}$ ). These results suggested that Rab31 may be associated with a poor prognosis of patients with OSCC.

Establishment of Rab31-knockdown OSCC cell lines. To assess the expression levels of Rab31 in cultured OSCC cells, the mRNA expression levels of Rab31 were determined in four OSCC cell lines (SCC-4, SCC-9, SCC25, and CAL-27); 
A

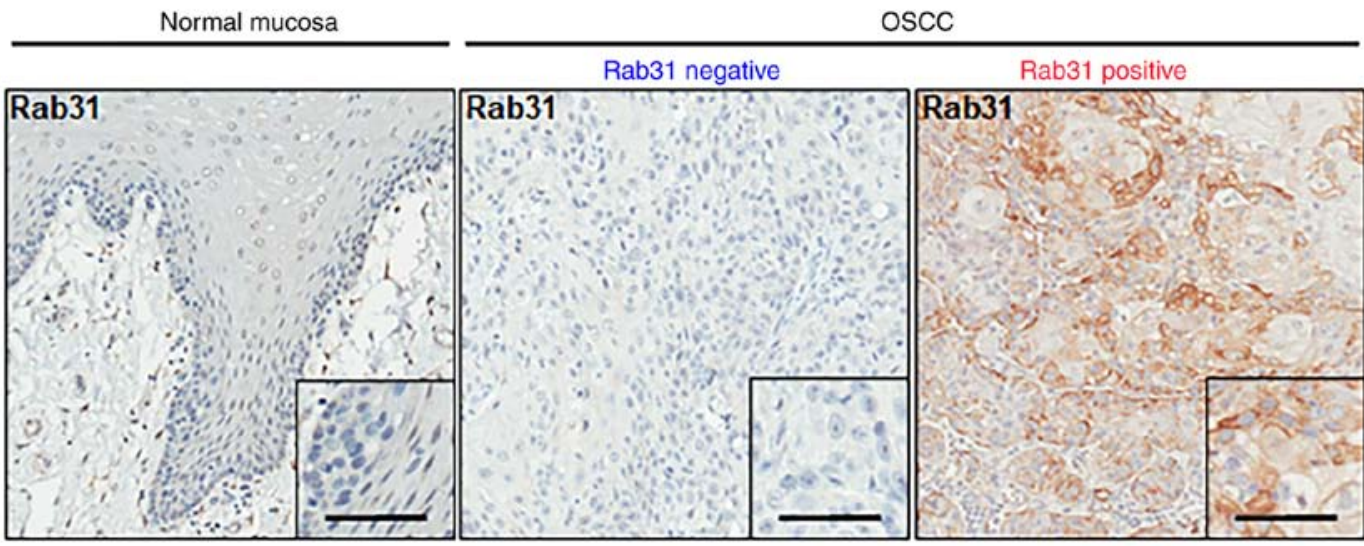

B
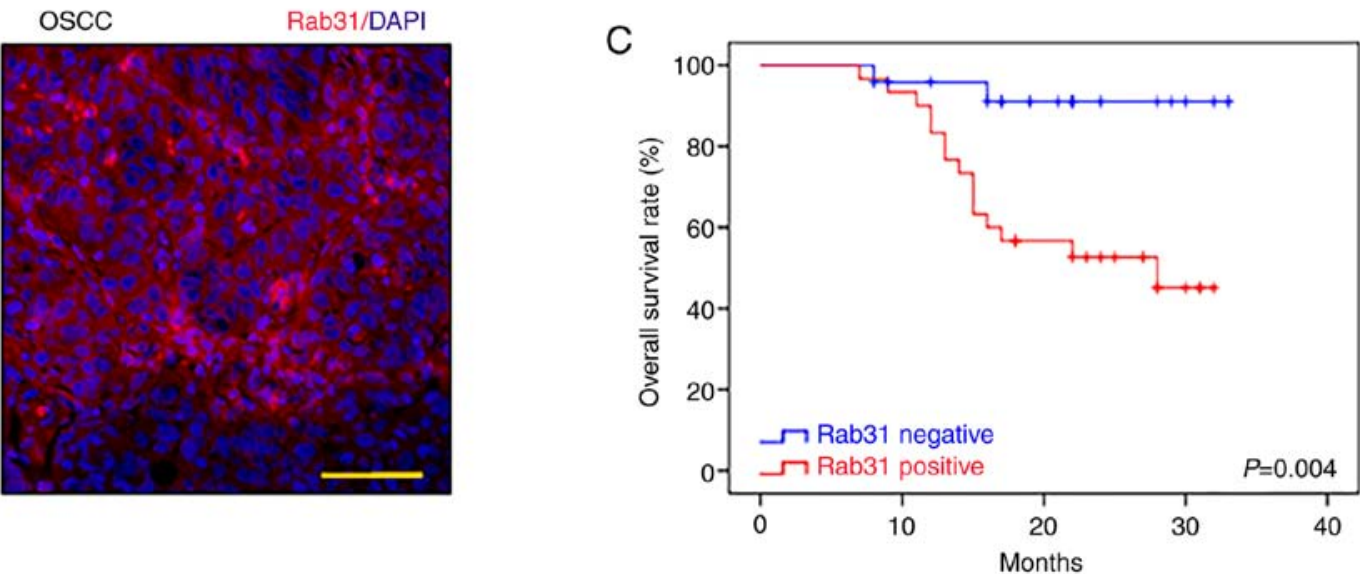

Figure 1. Rab31 expression levels are associated with poor prognosis in patients with OSCC. (A) Representative IHC staining images of normal mucosa, Rab31-negative and -positive OSCC. Scale bar, $50 \mu \mathrm{m}$. (B) Immunofluorescence indicated that Rab31 was mainly located in the cytoplasm of cancerous epithelial cells. Scale bar, $50 \mu \mathrm{m}$. (C) Kaplan-Meier curve analysis demonstrated that positive Rab31 expression was significantly associated with a poor prognosis of patients with OSCC. OSCC, oral squamous cell carcinoma.

Table III. Associations between patient clinicopathological characteristics and Rab31 expression levels

\begin{tabular}{lrrrr}
\hline & & \multicolumn{2}{c}{ Rab31 } & \\
\cline { 3 - 4 } Characteristic & Total & Negative & Positive & P-value \\
\hline Grade & & & & 0.016 \\
$\quad$ I & 12 & 9 & 3 & \\
$\quad$ II+III & 42 & 15 & 27 & \\
Tumor stage & & & & 0.363 \\
$\quad$ T1+T2 & 45 & 21 & 24 & \\
T3 & 9 & 3 & 6 & \\
Lymph node & & & & 0.799 \\
involvement & & & & \\
$\quad$ Negative & 35 & 16 & 19 & \\
Positive & 19 & 8 & 11 & \\
\hline
\end{tabular}

${ }^{\mathrm{a}}$ Fisher's exact test

primary cultured HOECs were used as the normal control (Fig. 2A). The SCC-9 cells exhibited no notable increase in Rab31 expression levels compared with those in the normal
HOECs. To establish Rab31-knockdown OSCC cell lines, two shRNAs (shRNA1 and shRNA2) were transduced into CAL-27, SCC-4 and SCC-25 cells. The selection of SCC-4 and SCC-25 cell lines was based on the successful Rab 31 knockdown, which was not observed in CAL-27 cells. Both shRNA1 and shRNA2 effectively downregulated the mRNA expression levels of Rab31 in SCC-4 and SCC-25 cells compared with those in the control groups; although shRNA2 appeared to be highly effective in the SCC-4 cell line, the results for SCC-25 were not satisfactory (Fig. 2B). Thus, to achieve efficient knockdown in both cell lines, shRNA1 against Rab31 (sh-Rab31) was selected for use in further experiments.

Silencing Rab31 inhibits OSCC cell proliferation and induces apoptosis. The effects of Rab31 on OSCC cell proliferation were next assessed. Compared with those in the corresponding control groups, silencing Rab31 significantly decreased the colony numbers and suppressed the proliferation of SCC-4 and SCC-25 cells (Fig. 3A-D). Additionally, the results of the flow cytometry assays revealed that Rab31 knockdown resulted in increased percentages of apoptotic SCC-4 (control, $7.67 \%$ vs. sh-Rab31, 21.20\%; P<0.001) and SCC-25 (control, $4.78 \%$ vs. sh-Rab31, 19.90\%; P<0.001) cells (Fig. 3E and F). Subsequent WB and RT-qPCR analyses demonstrated that 

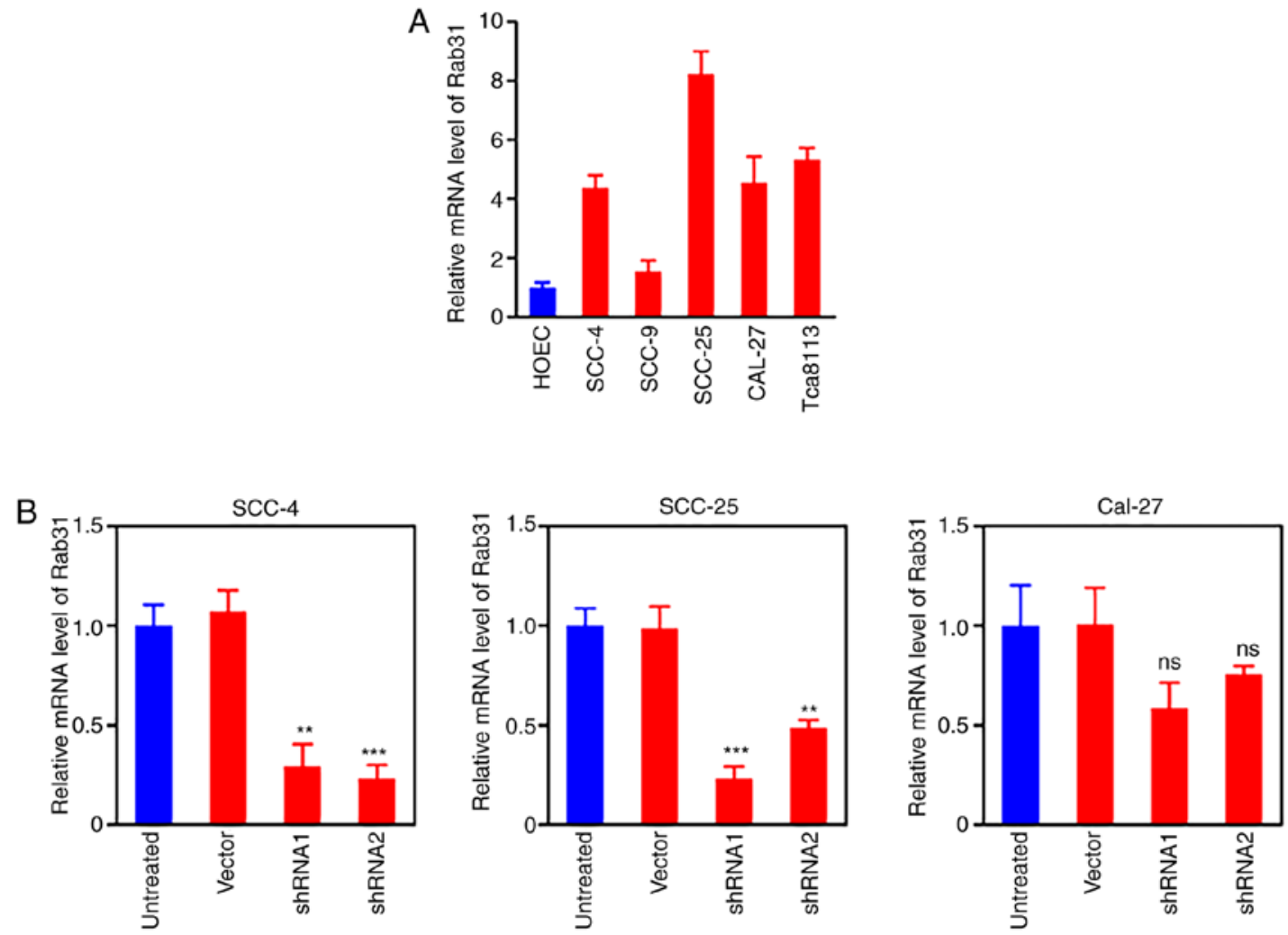

Figure 2. Establishment of Rab31-knockdown oral squamous cell carcinoma cell lines. (A) The mRNA levels of Rab31 in HOECs and human OSCC cell lines. (B) SCC-4 and SCC-25 cells were transfected with negative control or Rab31 shRNA1 and shRNA2; Both shRNA1 and shRNA2 significantly reduced the mRNA expression levels of Rab31 ${ }^{* *} \mathrm{P}<0.01$ and ${ }^{* * *} \mathrm{P}<0.001$ vs. vector. HOECs, human oral epithelial cells; shRNA, short hairpin RNA; vector, negative control shRNA.

Rab31 silencing reduced the expression levels of Survivin and cyclin D1, but increased the expression of Bcl-2 at the protein and mRNA levels compared with those in the control cells (Fig. 3G and H). These results suggested that Rab31 was associated with cell survival, the cell cycle and apoptosis.

Knockdown of Rab31 expression suppresses the invasive ability of OSCC cells. In the current study, the effects of Rab31 silencing on the invasive ability of OSCC cell lines were assessed using a Transwell invasion assay. The results demonstrated that knockdown of Rab31 expression significantly reduced the invasive capability of SCC- 4 and SCC-25 cells compared with that in the control groups (Fig. 4A and B). Additionally, the mRNA expression levels of two crucial markers of the epithelial-mesenchymal transition (EMT) were detected by RT-qPCR; the results revealed that compared with those in the control groups, Rab31 silencing significantly upregulated the mRNA expression levels of E-cadherin and downregulated the levels of N-cadherin (Fig. 4C). These results suggested a link between Rab31 and the EMT. The protein secretion of matrix metalloproteinase (MMP-9), an indispensable enzyme involved in tumor cell invasion, was detected by ELISA. Rab31 knockdown significantly decreased the MMP-9 protein levels in the supernatants of SCC-4 and SCC-5 cell cultures compared with those in the supernatants of the control-transfected cells (Fig. 4D).

Silencing Rab31 suppresses the growth of xenograft tumors. To determine the effects of Rab31 on OSCC cells in vivo, control $(\mathrm{n}=5)$ or sh-Rab31-transfected ( $\mathrm{n}=5)$ SCC-25 cells were inoculated into nude mice. The knockdown efficiency of sh-Rab31 in tumor tissues was tested and compared with that of the control vector (Fig. 5A). The tumor growth curves demonstrated that Rab31 silencing significantly suppressed tumor growth in vivo (Fig. 5B). On day 28, the mice were euthanized, and the tumors were harvested for further analysis. The results revealed that the tumor weight of the shRab31-treated group was significantly lower compared with that of the control group (Fig. 5C). IHC staining results demonstrated that compared with the control group, Rab31 silencing decreased the expression levels of survivin, Ki-67 and N-cadherin, but upregulated those of E-cadherin (Fig. 5D). These observations were in accordance with the results of the in vitro analyses.

\section{Discussion}

Rab31 is known to serve a number of roles in cancer progression (22); however, its role in human OSCC remains poorly understood. The current study examined the expression of Rab31 in resected OSCC tissue specimens. The results demonstrated that Rab31 expression was upregulated in human OSCC tissue samples compared with those from healthy subjects; further analysis identified the relationship between Rab31 expression and a poor prognosis in patients with OSCC. Knockdown of Rab31 expression inhibited cancer cell proliferation and induced apoptosis compared with those observed in the negative control-transfected cells. In addition, the results demonstrated that silencing Rab31 reduced the invasive ability 
A

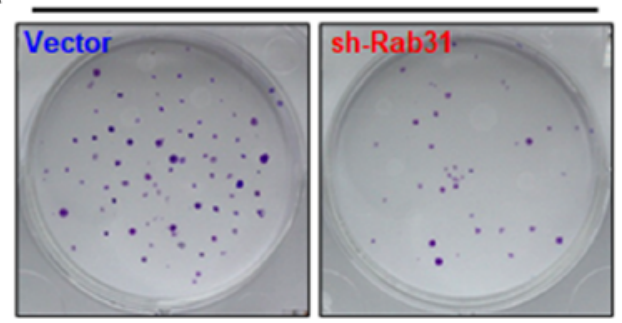

C
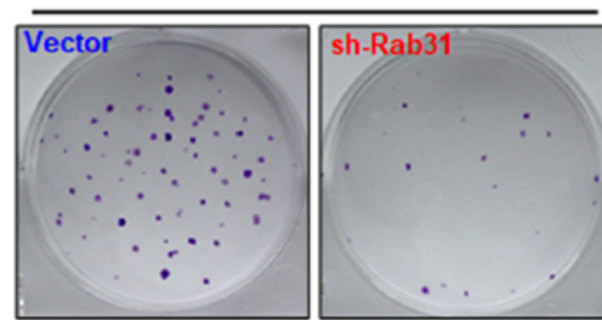

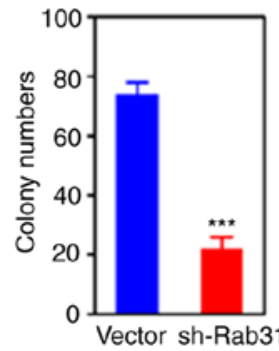

B

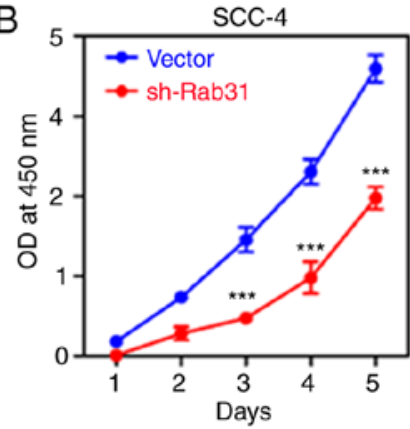

D
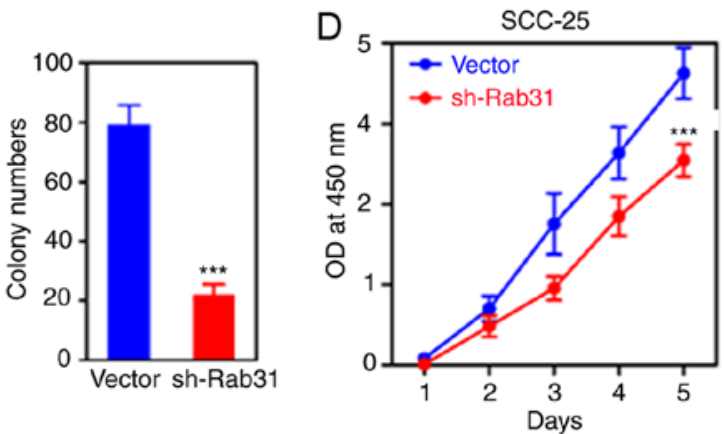

E
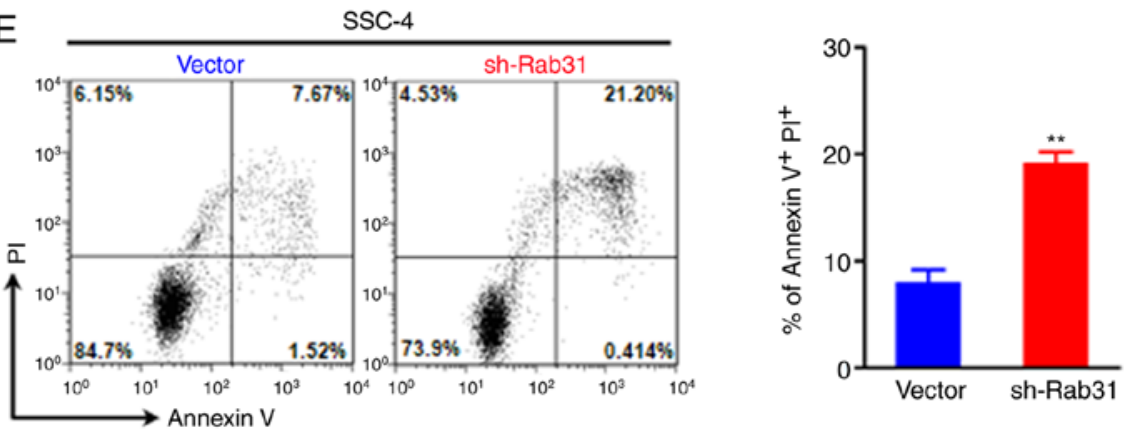

$\mathrm{F}$
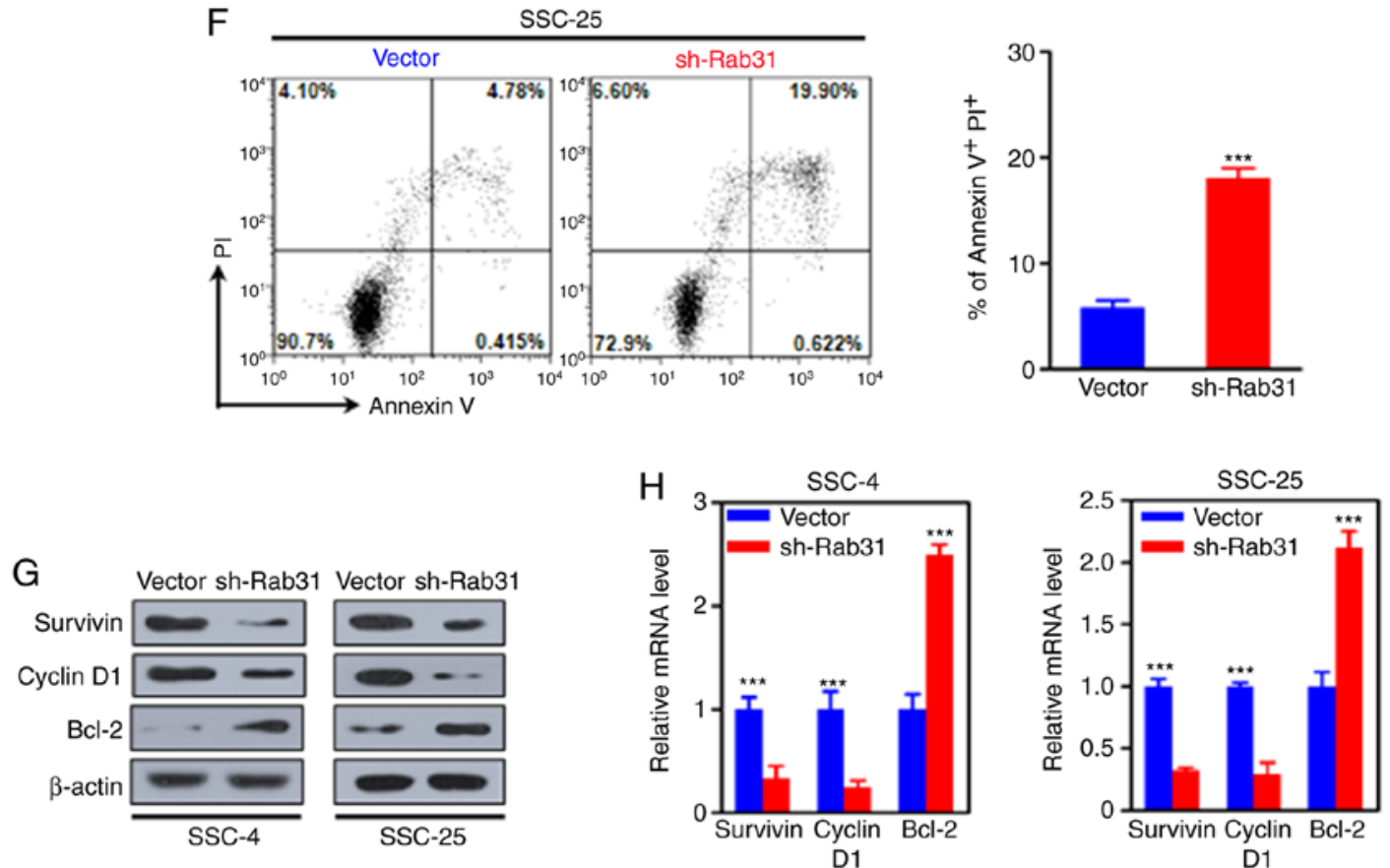

Figure 3. Rab31 knockdown suppresses oral squamous cell carcinoma cell proliferation and induces apoptosis. (A-D) Rab31 knockdown significantly reduced the colony numbers and repressed the proliferation of (A and B) SCC-4 and (C and D) SCC-25 cells compared with those in the control group. (E and F) Rab31 knockdown induced apoptosis of (E) SCC-4 and (F) SCC-25 cells. (G and H) Knockdown of Rab31 reduced the (G) protein and (H) mRNA levels of survivin and cyclin D1, but increased the protein levels of Bcl-2 in SCC-4 and SCC- 25 cells. ${ }^{* *} \mathrm{P}<0.01$ and ${ }^{* * * *} \mathrm{P}<0.001$ vs. vector. Vector, negative control short hairpin RNA; sh-Rab31, short hairpin RNA targeting Rab31; OD, optical density. 
A

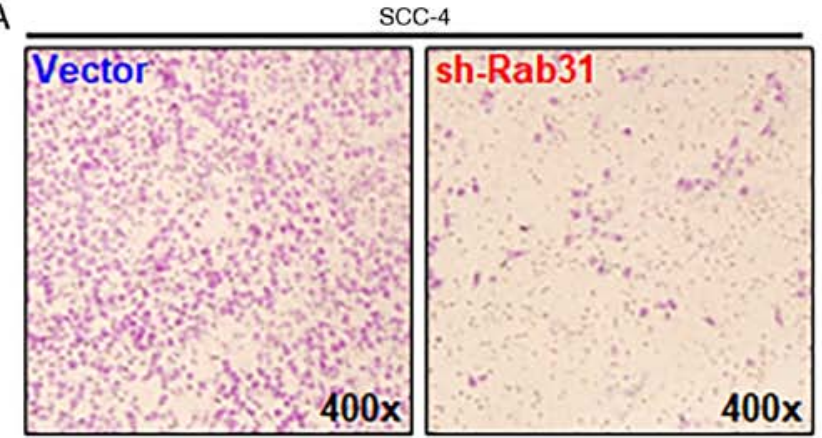

$\mathrm{B}$

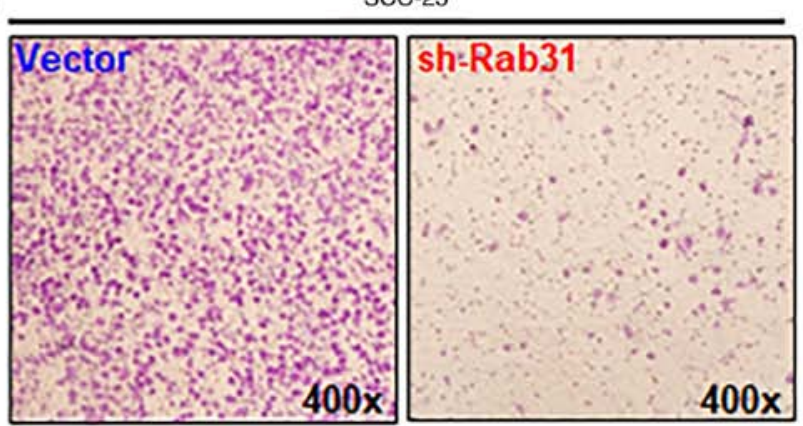

C
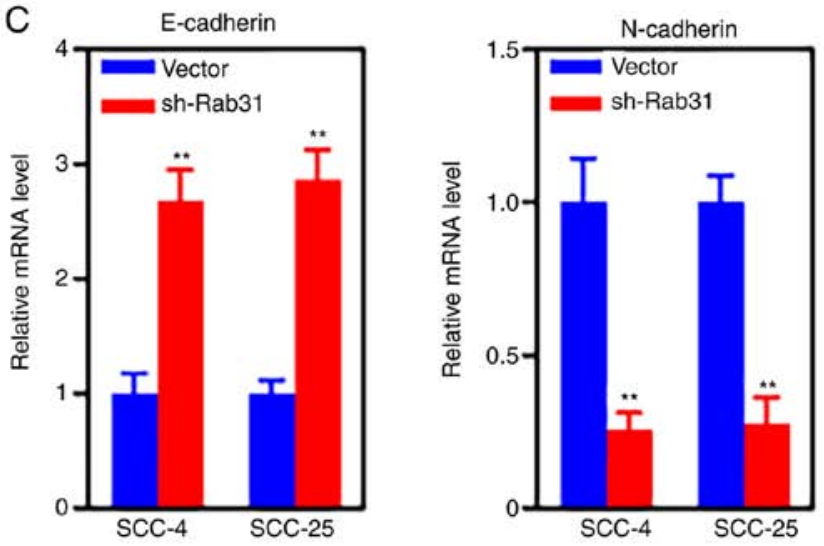
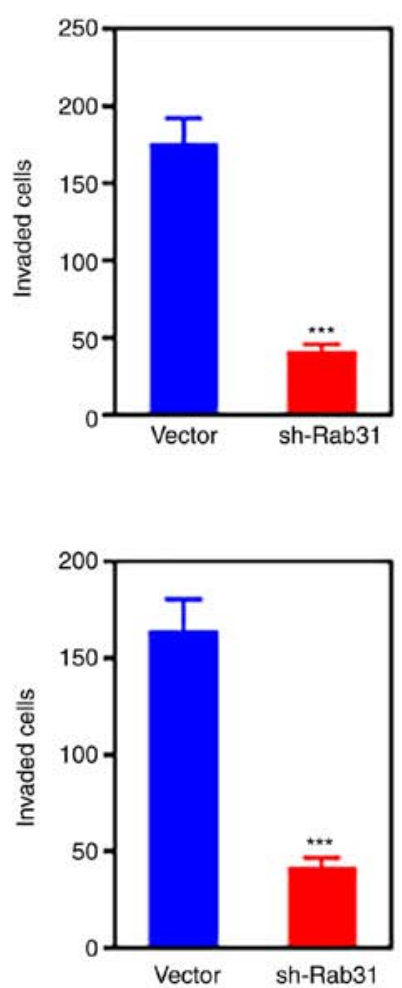

D

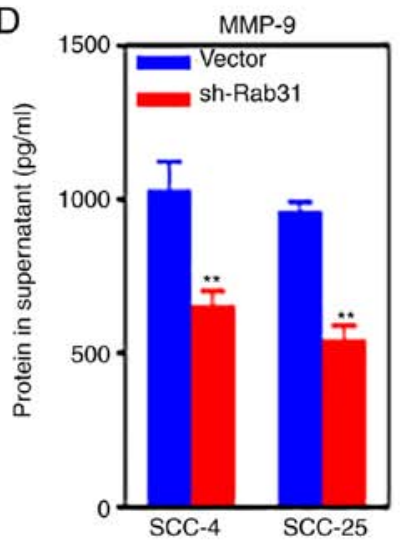

Figure 4. Rab31 knockdown suppresses the invasive capability of oral squamous cell carcinoma cells. (A and B) Rab31 knockdown significantly reduced the numbers of invasive (A) SCC-4 and (B) SCC-25 cells. (C) Knockdown of Rab31 upregulated the mRNA levels of E-cadherin and downregulated the mRNA levels of N-cadherin in SCC-4 and SCC-25 cells. (D) ELISA assay results revealed that Rab31 silencing significantly reduced the protein levels of MMP-9 in the supernatant of SCC-4 and SCC-25 cells. ${ }^{* *} \mathrm{P}<0.01$ and ${ }^{* * *} \mathrm{P}<0.001$ vs. vector. Vector, negative control short hairpin RNA; sh-Rab31, short hairpin RNA targeting Rab31.

of OSCC cells. Notably, in vivo experimental analysis revealed that knockdown of Rab31 expression suppressed tumor growth in Rab31-specific shRNA-transfected xenografts compared with that in the control group.

High expression levels of Rab31 have been reported in various types of cancer, including breast and ovarian cancer, glioblastoma and hepatocellular carcinoma (11,22-25). The results of the present study demonstrated a significant increase in Rab31 expression levels in OSCC samples compared with those in normal oral mucosa samples. In addition, OSCC cell lines presented with higher protein and mRNA expression levels of Rab31 compared with those in the normal oral mucosa cells. These results were consistent with those of previous studies. Rab31 mRNA expression levels have been previously identified to be elevated in a cisplatin-resistant OSCC cell line via Affymetrix microarray analysis (26). Additionally, differential gene expression profiling revealed Rab31 to be among a number of genes exhibiting upregulated expression by cDNA microarray analysis in a pingyangmycin-resistant cell line compared with non-resistant cell lines (27). Furthermore, the expression of Rab31 has been associated with the clinicopathological characteristics of certain types of cancer. In hepatocellular carcinoma, high expression levels of Rab31 have been reported to be a predictive factor for a poor prognosis, which is independent of advanced TNM staging and intrahepatic metastasis (24). Additionally, high Rab31 mRNA expression levels have been reported to be associated with distant metastasis-free and overall survival in a multivariate 

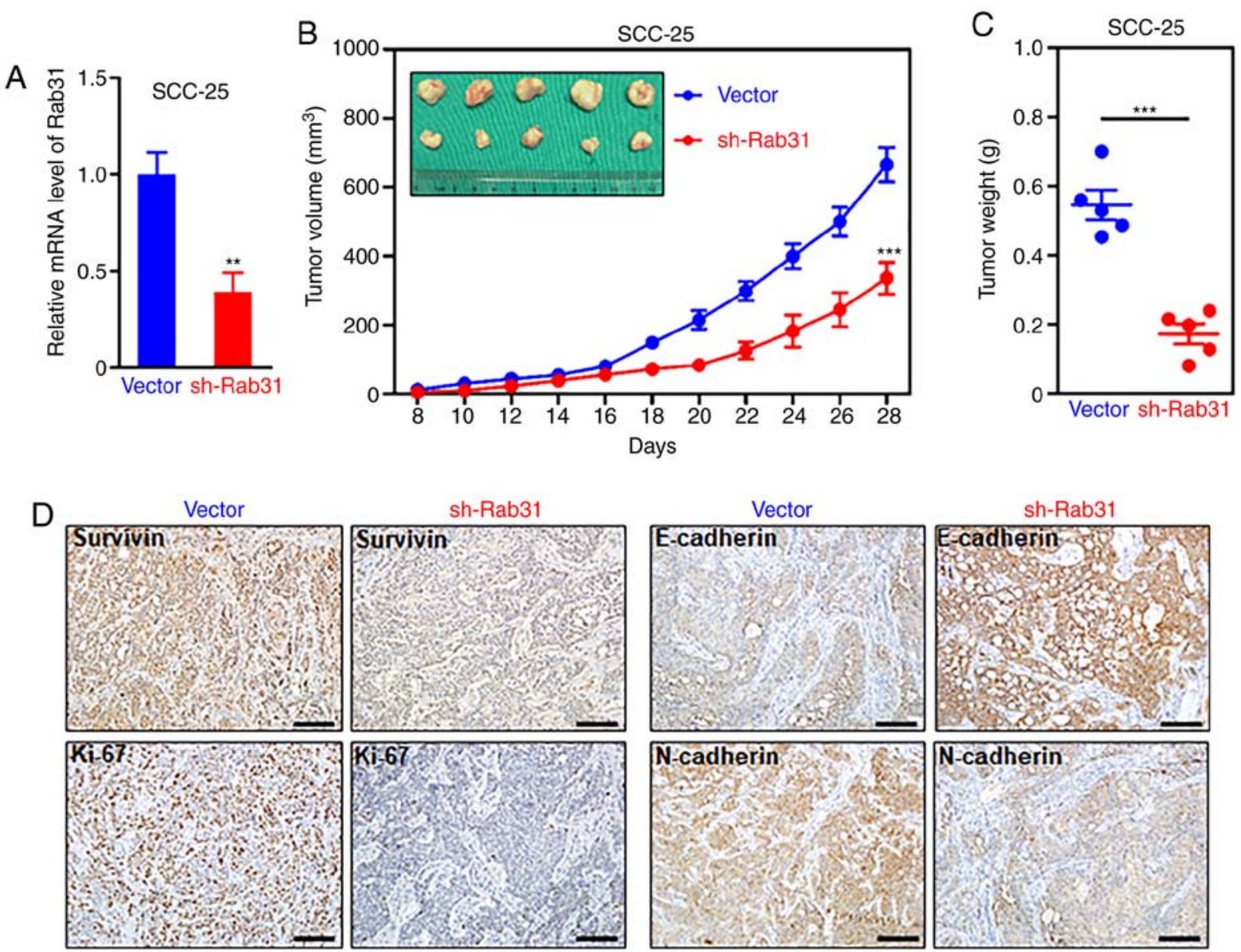

Figure 5. Rab31 knockdown suppresses the growth of oral squamous cell carcinoma xenograft tumors. (A) Evidence of the knockdown efficiency of sh-Rab31. ${ }^{* *} \mathrm{P}=0.041$. (B) Images and growth curve of xenograft tumors formed from SCC-25 cells transfected with negative control or Rab31 shRNA. Rab31 knockdown significantly repressed tumor growth in vivo. (C) Tumor weight in the negative control and sh-Rab31 groups on day 28. (D) Representative immunohistochemistry images of the xenograft tumors tissues. Silencing Rab31 reduced the expression levels of survivin, Ki-67 and N-cadherin, and upregulated the expression levels of E-cadherin compared with those in the negative control group. Scale bar, $50 \mu \mathrm{m} .{ }^{* * *} \mathrm{P}<0.001$ vs. vector. Vector, negative control short hairpin RNA; sh-Rab31, short hairpin RNA targeting Rab31.

analysis of breast cancer (28); however, no associations have been identified between Rab31 expression levels and overall or progression-free survival in advanced ovarian cancer (29). The results of the present study suggested that positive expression of Rab31 may be associated with a high pathological grade and poor prognosis in patients with OSCC.

The present study revealed the potential role and the underlying mechanism of Rab31 in OSCC. In the present study, knockdown of Rab31 expression attenuated OSCC cell colony formation and proliferation rates compared with those in the control cells, as determined by colony formation and CCK- 8 proliferation assays. Cyclin D1 and Survivin serve pivotal roles in tumor cell proliferation (30). The results of the present study demonstrated that Rab31 silencing suppressed the protein and mRNA expression levels of cyclin D1 and Survivin. Bcl-2 has been reported to be a key mediator of the apoptotic response to anticancer treatment (31). The results of the current study demonstrated that knockdown of Rab31 expression resulted in the induction of Bcl-2 expression. A previous study has reported that silencing Rab31 expression suppresses the proliferation and induced apoptosis in MHCC97 cells, whereas ectopic expression of Rab31 leads to an increase in the Bcl-2/Bax ratio by activating the phosphoinositide 3-kinase/protein kinase
B (AKT) signaling pathway (23). The indirect interaction between Rab family proteins and Bcl-2 are further supported by another study in gastric cancer, which has demonstrated that inhibition of Rab9 expression leads to increased levels of Bax and decreased levels of $\mathrm{Bcl}-2$, triggering apoptosis (20). In addition, overexpression of Rab31 decreases the adhesion and invasion and promotes the proliferation of breast cancer cells, which results in a transition from an invasive to a proliferative phenotype (12). The results of the present study also demonstrated that Rab31 silencing inhibited the invasive ability of OSCC cell lines. E-cadherin and N-cadherin are markers of the EMT (32). During the EMT process, epithelial cells obtain migratory and invasive properties, and lose cell-cell adhesion, accompanied by an increase in $\mathrm{N}$-cadherin and a decrease in E-cadherin expression levels (33). The present study demonstrated that Rab31 silencing downregulated the mRNA expression levels of $\mathrm{N}$-cadherin and upregulated those of E-cadherin. These results were in agreement with those of a study by Zhang et al (32) on Rab3D in esophageal cancer cells involving the PI3K/Akt signaling pathway, in which knockdown of Rab3D significantly suppressed esophageal cancer cell migration and invasion and accordingly altered EMT-related markers, including the upregulation E-cadherin 
and downregulation of $\mathrm{N}$-cadherin expression levels. However, the positive in vitro results did not correspond to the negative in vivo results in the present study, as no significant associations were observed between lymph node metastasis and Rab31 expression in human tissues. These negative results, to the best of our knowledge, may have occurred due to the design of the pathological sample study (comparisons among different patients rather than tissues from the same patient) and the limited sample size of the current study. On the other hand, Rab31 is also regulated by MUC1 proteins and the interaction of $\mathrm{u}$-plasminogen activator receptor with the cation-independent mannose 6-phosphate receptor complex (22), which may affect the expression and functions of Rab31. Such contradictory in vitro and in vivo results have also been observed in a study of breast cancer (12). Notably, when Rab31 was overexpressed in breast cancer cell lines, it enhanced the cell proliferation, diminished adhesion mediated through several extracellular matrix components, and attenuated invasion in vitro; however, when breast cancer cells moderately overexpressing Rab31 were xenografted into nude mice, they exhibited significantly reduced lung metastasis compared with that observed in control cell xenografts (12). The present results are consistent with those of the aforementioned study, suggesting a complicated molecular loop system regulating the oncogenic potential of Rab31.

OSCC cells exhibit high levels of MMP-9, and targeting MMPs by selective gelatinase peptides inhibits the invasion of oral tongue squamous cell carcinoma $(33,34)$. Rab27a, Rab27b and Rab27 effector proteins are involved in assembly at fusion sites before and during the exocytosis of MMP-9, and these components are lost from sites of exocytosis when MMP-9 is released (35). A direct relationship between Rab family proteins and MMP-9 release has been observed and speculated in a study Stephens et al (36). In the present study, the protein levels of MMP-9 in the supernatant obtained from OSCC cells were measured by ELISA; knockdown of Rab31 expression significantly reduced MMP-9 secretion compared with that in the control-transfected cells. Previous studies have focused on other types of cancer and reported similar results. For example, in glioblastoma and cervical cancer, Rab31 serves a crucial role in cell proliferation by promoting G1/S transition and regulating the expression levels of cell cycle-related proteins, such as cyclins D1, A and B1 $(23,30)$. In addition, Rab31-induced cervical cancer cell proliferation and migration require the phosphorylation of AKT and extracellular signal-regulated kinase 1/2 (23). Rab31 knockdown in cervical cancer cells decreases the protein and mRNA expression levels of N-cadherin and upregulates those of E-cadherin (23). Taken together, these studies indicate the essential roles of Rab31 in the proliferation and migration of human OSCC.

In conclusion, upregulation of Rab31 expression levels was detected in OSCC tissues compared with those from healthy subjects, and it was associated with a high pathological grade and short survival. The results of the present study also demonstrated that Rab31 contributed to the proliferation and invasion of OSCC cells. In addition, Rab31 knockdown induced apoptosis in OSCC cells in vitro and suppressed xenograft tumor growth in vivo. These results suggested that Rab31 may be exploited for the development of a therapeutic agent for OSCC.

\section{Acknowledgements}

Not applicable.

\section{Funding}

This work was supported by The National Natural Science foundation Project (grant no. 81570949), The Excellent Subject Leader Plan of Shanghai Municipal Commission of Health and Family Planning (grant no. 2017BR019), The Youth Project of Shanghai Municipal Commission of Health and Family Planning (grant no. 20164Y0067), The Science and Technology Commission of Shanghai Municipality, Natural Science Grant (grant no. 19ZR1430000) and The Hospital Innovation Project (grant no. CK2019004).

\section{Availability of data and materials}

All data generated or analyzed during this study are included in this published article.

\section{Authors' contributions}

YH and CM conceived and designed the study, and contributed to data interpretation, obtaining the patient information and revising the manuscript. CM acquired the pathological specimens. XL and FZ performed most of the experiments. XL and FZ confirm the authenticity of all the raw data. ZL, XT, YH and $\mathrm{JJ}$ conducted a part of the in vivo and in vitro transfection experiments. All authors read and approved the final manuscript.

\section{Ethics approval and consent to participate}

All patients' samples were used under written approval by the patients. All experiments in the present study were approved by the Independent Ethics Committee and Animal Experimental Ethical Inspection of the Shanghai Ninth People's Hospital, Shanghai Jiao Tong University School of Medicine (Shanghai, China) and performed at the Shanghai Ninth People's Hospital (approval nos. SH9H-2019-T117-1 for human tissues and HKDL-2017-304 for animal studies).

\section{Patient consent for publication}

Not applicable.

\section{Competing interests}

The authors declare that they have no competing interests.

\section{References}

1. Siegel RL, Miller KD and Jemal A: Cancer Statistics, 2017. CA Cancer J Clin 67: 7-30, 2017.

2. Choi S and Myers JN: Molecular pathogenesis of oral squamous cell carcinoma: Implications for therapy. J Dent Res 87: 14-32, 2008.

3. Hunter KD, Parkinson EK and Harrison PR: Profiling early head and neck cancer. Nat Rev Cancer 5: 127-135, 2005.

4. Wang YJ, Zhang ZF, Fan SH, Zhuang J, Shan Q, Han XR Wen X, Li MQ, Hu B, Sun CH, et al: MicroRNA-433 inhibits oral squamous cell carcinoma cells by targeting FAK. Oncotarget 8 : 100227-100241, 2017. 
5. Bonner JA, Harari PM, Giralt J, Cohen RB, Jones CU, Sur RK, Raben D, Baselga J, Spencer SA, Zhu J, et al: Radiotherapy plus cetuximab for locoregionally advanced head and neck cancer: 5 -year survival data from a phase 3 randomised trial, and relation between cetuximab-induced rash and survival. Lancet Oncol 11: 21-28, 2010.

6. Chia WJ and Tang BL: Emerging roles for Rab family GTPases in human cancer. Biochim Biophys Acta 1795: 110-116, 2009.

7. Recchi $C$ and Seabra MC: Novel functions for Rab GTPases in multiple aspects of tumour progression. Biochem Soc Trans 40 1398-1403, 2012

8. Chen D, Guo J, Miki T, Tachibana M and Gahl WA: Molecular cloning of two novel rab genes from human melanocytes. Gene 174: 129-134, 1996.

9. Klopper TH, Kienle N, Fasshauer D and Munro S: Untangling the evolution of Rab G proteins: Implications of a comprehensive genomic analysis. BMC Biol 10: 71, 2012.

10. Ng EL, Wang Y and Tang BL: Rab22B's role in trans-Golg network membrane dynamics. Biochem Biophys Res Commun 361: 751-757, 2007.

11. Abba MC, Hu Y, Sun H, Drake JA, Gaddis S, Baggerly K, Sahin A and Aldaz CM: Gene expression signature of estrogen receptor alpha status in breast cancer. BMC Genomics 6: 37, 2005.

12. Grismayer B, Solch S, Seubert B, Kirchner T, Schäfer S, Baretton G, Schmitt M, Luther T, Krüger A, Kotzsch M and Magdolen V: Rab31 expression levels modulate tumor-relevant characteristics of breast cancer cells. Mol Cancer 11: 62, 2012.

13. Pu SY, Yu Q, Wu H, Jiang JJ, Chen XQ, He YH and Kong QP ERCC6L, a DNA helicase, is involved in cell proliferation and associated with survival and progress in breast and kidney cancers. Oncotarget 8: 42116-42124, 2017.

14. Amornphimoltham P, Rechache K, Thompson J, Masedunskas A, Leelahavanichkul K, Patel V, Molinolo A, Gutkind JS and Weigert R: Rab25 regulates invasion and metastasis in head and neck cancer. Clin Cancer Res 19: 1375-1388, 2013.

15. Clausen MJ, Melchers LJ, Mastik MF, Slagter-Menkema L, Groen HJ, Laan BF, van Criekinge W, de Meyer T, Denil S, van der Vegt B, et al: RAB25 expression is epigenetically downregulated in oral and oropharyngeal squamous cell carcinoma with lymph node metastasis. Epigenetics 11: 653-663, 2016.

16. Zhang D, Lu C and Ai H: Rab5a is overexpressed in oral cancer and promotes invasion through ERK/MMP signaling. Mol Med Rep 16: 4569-4576, 2017

17. Bao Q, Liao X, Li R and Ding N: KCNQ1OT1 promotes migration and inhibits apoptosis by modulating miR-185-5p/Rab14 axis in oral squamous cell carcinoma. Dev Growth Differ 61: 466-474, 2019

18. Zhu Y, Shi F, Wang $M$ and Ding J: Knockdown of Rab9 suppresses the progression of gastric cancer through regulation of Akt signaling pathway. Technol Cancer Res Treat 19: 1533033820915958, 2020.

19. Pollaers K, Hinton-Bayre A, Friedland PL and Farah CS: AJCC 8th Edition oral cavity squamous cell carcinoma staging-Is it an improvement on the AJCC 7th Edition? Oral Oncol 82: 23-28, 2018.

20. Wang H, Bao W, Jiang F, Che Q, Chen Z, Wang F, Tong H, Dai C, He X, Liao Y, et al: Mutant p53 (p53-R248Q) functions as an oncogene in promoting endometrial cancer by up-regulating REG $\gamma$. Cancer Lett 360: 269-279, 2015.

21. Livak KJ and Schmittgen TD: Analysis of relative gene expression data using real-time quantitative PCR and the 2(-Delta Delta C(T)) method. Methods 25: 402-408, 2001.

22. Chua CE and Tang BL: The role of the small GTPase Rab31 in cancer. J Cell Mol Med 19: 1-10, 2015.
23. Pan Y, Zhang Y, Chen L, Liu Y, Feng Y and Yan J: The Critical Role of Rab31 in cell proliferation and apoptosis in cancer progression. Mol Neurobiol 53: 4431-4437, 2016.

24. Sui Y, Zheng X and Zhao D: Rab31 promoted hepatocellular carcinoma (HCC) progression via inhibition of cell apoptosis induced by PI3K/AKT/Bcl-2/BAX pathway. Tumour Biol 36: 8661-8670, 2015.

25. Kotzsch M, Kirchner T, Soelch S, Friedrich K, Baretton G, Magdolen V and Luther T: Inverse association of rab31 and mucin-1 (CA15-3) antigen levels in estrogen receptor-positive $(\mathrm{ER}+)$ breast cancer tissues with clinicopathological parameters and patients' prognosis. Am J Cancer Res 7: 1959-1970, 2017.

26. Zhang P, Zhang Z, Zhou X, Qiu W, Chen F and Chen W: Identification of genes associated with cisplatin resistance in human oral squamous cell carcinoma cell line. BMC Cancer 6: 224, 2006.

27. Zheng G, Zhou M, Ou X, Peng B, Yu Y, Kong F, Ouyang Y and $\mathrm{He} \mathrm{Z}$ : Identification of carbonic anhydrase 9 as a contributor to pingyangmycin-induced drug resistance in human tongue cancer cells. FEBS J 277: 4506-4518, 2010.

28. Kotzsch M, Sieuwerts AM, Grosser M, Meye A, Fuessel S, Meijer-van Gelder ME, Smid M, Schmitt M, Baretton G, LutherT, etal:Urokinase receptor splice variant uPAR-del4/5-associated gene expression in breast cancer: Identification of rab31 as an independent prognostic factor. Breast Cancer Res Treat 111: 229-240, 2008

29. Kotzsch M, Dorn J, Doetzer K, Schmalfeldt B, Krol J, Baretton G, Kiechle M, Schmitt M and Magdolen V: mRNA expression levels of the biological factors UPAR, uPAR-del $4 / 5$, and rab31, displaying prognostic value in breast cancer, are not clinically relevant in advanced ovarian cancer. Biol Chem 392: 1047-1051, 2011.

30. Li Z, Cui J, Yu Q, Wu X, Pan A and Li L: Evaluation of CCND1 amplification and CyclinD1 expression: diffuse and strong staining of CyclinD1 could have same predictive roles as CCND1 amplification in ER positive breast cancers. Am J Transl Res 8: 142-153, 2016.

31. Zhang W, Liu Y, Li YF, Yue Y, Yang X and Peng L: Targeting of survivin pathways by YM155 inhibits cell death and invasion in oral squamous cell carcinoma cells. Cell Physiol Biochem 38: 2426-2437, 2016

32. Zhang J, Kong R and Sun L: Silencing of Rab3D suppresses the proliferation and invasion of esophageal squamous cell carcinoma cells. Biomed Pharmacother 91: 402-407, 2017.

33. Henriques AC, de Matos FR, Galvao HC and Freitas Rde A: Immunohistochemical expression of MMP-9 and VEGF in squamous cell carcinoma of the tongue. J Oral Sci 54: 105-111, 2012.

34. Heikkila P, Suojanen J, Pirila E, Väänänen A, Koivunen E, Sorsa $\mathrm{T}$ and Salo T: Human tongue carcinoma growth is inhibited by selective antigelatinolytic peptides. Int J Cancer 118: 2202-2209, 2006.

35. Bobrie A, Krumeich S, Reyal F, Recchi C, Moita LF, Seabra MC, Ostrowski $\mathrm{M}$ and Théry C: Rab27a supports exosome-dependent and -independent mechanisms that modify the tumor microenvironment and can promote tumor progression. Cancer Res 72: 4920-4930, 2012.

36. Stephens DC, Osunsanmi N, Sochacki KA, Powell TW, Taraska JW and Harris DA: Spatiotemporal organization and protein dynamics involved in regulated exocytosis of MMP-9 in breast cancer cells. J Gen Physiol 151: 1386-1403, 2019.

This work is licensed under a Creative Commons Attribution-NonCommercial-NoDerivatives 4.0 International (CC BY-NC-ND 4.0) License. 